\title{
Diversity In Supply Chains: What Really Matters?
}

Gwendolyn Whitfield, Ph.D., Pepperdine University, USA

Dan Farrell, Ph.D., Western Michigan University, USA

\begin{abstract}
Diverse, well-developed supply chains promote business success by reducing costs, enhancing innovation, successfully integrating acquired businesses and reaching new markets. Managing such inter-organizational relationships improves when the organizational culture is humanistic, achievement oriented, affiliative and self-actualizing and when similar perceptions of these values are held across all buyer and supplier groups. Based on a survey of a diverse group of supplier chief executive officers $(n=70)$ and buyers in a focal organization $(n=79)$, this study finds that African-American executives are less likely to perceive constructive dimensions of organizational culture, while Hispanic executives are more likely to perceive negative dimensions, while buyers perceive the culture as constructive for a culture of diversity.
\end{abstract}

Keywords: Culture of Diversity, Supply Chain, SME

\section{INTRODUCTION}

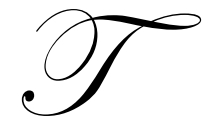

he linkage between corporate employee diversity and firm performance is well established (Hollowell, 2007; Eroglu, Thornton, \& Bellenger, 2005). A diversity inclusive corporate culture is said to improve innovation and adaptiveness in the heterogeneous market segments faced by international companies (Gomez-Mejia \& Palich, 1999). More recently, building diverse supply chains is seen as an additional effective means of increasing a firm's performance similar to employee diversity (Crook, Giunipero, Reus, Handfield, \& Williams, 2008). Well managed supply chains provide a form of "interorganizational relationship" (Crook, et al., 2008), that is a managed structure standing between full market and internal production only models. Such supply chains have demonstrated an ability to reduce costs, reduce order cycles, enhance product innovation, and improve technology implementation (Bowersox, Closs, \& Stank, 2003; Crook, et al, 2008; Stock \& McDermott, 2000). Successful management of supply has been linked to common governance characteristics (Golicic \& Mentzer, 2005) and similar human resource practices (Koulikoff-Souviron \& Harrison, 2007). Leading research has begun to look at organizational culture and how it can impact supply chain performance (Mello \& Stank, 2005; Burgess, Singh, \& Koroglu, 2006; Whitfield \& Landeros, 2006).

What is missing in the studies of organizational culture and supply chains is a stakeholder perspective such that internal and external perspectives or differences between buyer and supplier perspectives can be understood (Fraser \& Zarkada-Fraser, 2003). Research has shown different organizational stakeholders have varied perceptions of organizational social phenomena such as goal acceptance, the importance given to different dimensions of managerial performance, and the impact of management actions (Fraser \& Zarkada-Fraser, 2003). Thus, since 2002, (McAfee, Glassman, \& Honeycutt, 2002) supply chain has begun to be viewed as a manifestation of organizational culture. A high degree of cultural consistency and deeper cultural understanding has led to more successful supply management strategies (Whitfield \& Landeros, 2006). Decisions such as the number of suppliers per part, forecast horizons, and level of exports are influenced by the culture surrounding the supply chain (Mello \& Stank, 2005).

\section{DIVERSITY CULTURES}

Positive supplier diversity cultures are those that encourage broad supplier selection, foster supplier development, conduct fair and objective supplier evaluation, and ultimately increase diversity supplier spends 
(Whitfield and Landeros, 2006). Key elements of culture associated with success in these initiatives are communication (Smith, 2008; Morgan, 2005), commitment, and process integration (Dozbaba, 2000; Yuva, 2003). More specifically, the different norms and values that make up corporate culture are associated with diversity sourcing (Whitfield and Landeros, 2006). These values can be seen as a continuum where the best cultures are supportive (Smith, 2008) and constructive (Crook, Giunipero, et al., 2008). These positive cultures for diversity exhibit behaviors of communication that are problem oriented, spontaneous, empathetic (Smith, 2008), encouraging, self-actualizing, and affirmative (Whitfield \& Landeros, 2006). At the opposite end of the continuum, cultures unsupportive of diversity exhibit more evaluativeness, are more oppositional, and are more competitive and more perfectionistic (Smith, 2008; Whitfield \& Landeros, 2006).

Studies of diversity culture and supply chain management success focus on the shared values, beliefs, and patterns of behavior within and between firms in a supply chain (McAfee, Glassman, \& Honeycutt, 2002). Consistency of cultural perceptions is seen as fundamental to project alignment (Barinaga, 2007; Buttner, Lowe, \& Billings-Harris, 2006) and information exchange (Ambrose, Marshall, Fynes, \& Lynch, 2006; Low, 2004; Sheu, Yen \& Chae, 2006). Overall, successfully leveraging the benefits of supplier diversity has been consistently tied to well-developed cultures of organizational diversity (Buttner, et al., 2006; Crook, et al, 2008; Mello \& Stank, 2005; Stalinski, 2004; Whitfield \& Landeros, 2006).

\section{DEMOGRAPHICS AND PERCEPTIONS OF CULTURE}

Cultural consistency and shared perceptions may be inhibited by barriers expressed consciously or unconsciously, as well as in routine practices, procedures, and policies (McCarty Kilian, Hukai, 2005; Miller, 1998). Demographic dissimilarity has been associated with expectations that newcomers simply adopt the values of the organization, often a dominant white male culture (Ofori-Diankwa \& Reddy, 2007). Expecting the diversity group to accept the burden of change often produces short-term relationship conflict (Lankau, Ward, Amason, Ng, Sonnefeld, \& Agle, 2007), delaying the larger benefits of diversity.

Minority-owned businesses have been a growing segment of the U.S. economy, nearly doubling as a percent of the economy from the mid 1990s to the early 2000s (U.S. Small Business Association, 2001). On the supply side, this growth has become a business necessity (Eroglu, Green Thornton \& Bellenger, 2001) not just an ethical and moral concern, much like employee diversity (Hollowell, 2007). Indications are, however, that the two largest ethnic groups, Hispanics and African-Americans, have significantly different value orientations (Enz, Dollinger, \& Dailey, 1990; Eroglu, et al., 2005) compared to majority groups. These racial and ethnic cultural differences create communication interface complexities (Kaufman, 2001) that must be addressed to obtain improved work processes and outcomes (Chatman, Polzen, Barsade, \& Neale, 1998; Martin, 2005). Typically, being small to mid-size minority-owned suppliers often have less formalized decision processes, greater propensity for uncertainty avoidance, and more emphasis on participation and consideration (Eroglu, et al.). In addition to objective criteria, vendor assessments involve subjective factors and psychological tradeoffs among solution criteria (Eroglu, et al.); thus, it is reasonable to expect "buyers' personal values play a role in supplier selection procedures" (p. 35).

An emphasis on gender equity has increased labor force participation such that women are now 46 percent of the labor force (U.S. Department of Labor, 2004). Gender may also influence perceptions of organizational culture because "males and females process information differently, communicate differently" (Helms and Stern, 2001, p. 419) and have "different background experiences, find different information cues relevant, and have different schema for processing information" (Helms and Stern, 2001, p. 418). Other research suggests more complex effects for gender in supply chain cultures. While there is a significant set of findings indicating that gender similarity makes prospects more attractive (Dwyer, Orlando, \& Shepherd, 1998), among buyers, differences in trust, credibility, and customer orientation between gender groups are minimal and "probably not managerially significant" (Pullins, Reid, \& Plank, 2004, p. 40). Considering managerial behavior more generally, women fitting gender stereotypes are seen as less effective (Comer \& Jolson, 1991) and women evaluating other women is said to produce a more objective assessment (Elkins, Phillips, \& Ward, 2008).

Past research on the third classic demographic variable - age - will likely grow now that the generation following the baby boomers is the largest generational group in the workplace (Farrell \& Farrell, 2009). In buyer 
seller relationships, age similarity was found to have no significant effect when tested in the context of similarity attraction theory (Dwyer, Orlando, \& Shepherd, 1998). "Others have found that similarity in age improves communication as it affects perception about the organization's culture" (Helms \& Stern, 2001, p. 419). The general belief is that older employees are more likely to share top management perspectives and to have a more positive assessment of organizational culture (Lankau, Ward, Amason, Ng, Sonnefeld, \& Agle, 2007).

Based on these research summaries, this research tests differences in perceptions between suppliers and corporate buyers. Significant differences in diversity groups may identify groups where there may be special challenges in communication and the understanding necessary to experience the benefits of chain diversity. More significantly, this research tests the following three hypotheses:

$\mathbf{H}_{1}$ : Ethnic minority suppliers are less likely to perceive positive elements of organizational cultures than nonminority suppliers and more likely to perceive negative elements.

$\mathbf{H}_{2}$ : $\quad$ Female suppliers are less likely to perceive positive elements of organizational culture than male suppliers and more likely to perceive negative elements.

$\mathbf{H}_{3}$ : Older suppliers are more likely to perceive positive elements of organizational culture and less likely to perceive negative elements than younger suppliers.

\section{METHODOLOGY}

\section{Sample}

A web-enabled questionnaire was sent to the chief executive officers of 146 supplier firms doing business with a heavy equipment manufacturing firm. Seventy responses were received for an effective response rate of 47 percent. Of the seventy responses received, 29 (41.4 percent) were from ethnic minority or female supplier executives. The ages of these executives varied from as young as 30-39 years old (34.2 percent) to over 60 years old (5.3 percent). One hundred twelve corporate buyers were also sent a questionnaire. Seventy-nine responses were received (70 percent). This sample is 84 percent Caucasian.

\section{Survey Instrument}

The instrument used to measure organizational culture is the Organizational Culture for Diversity Inventory (OCDI). The OCDI has been used to analyze culture in over 100 organizations (Crook \& Szumal, 1993). It is a selfreporting attitude scale that measures 12 sets of normative beliefs. There are ten items for each of the 12 belief sets. The questions describe behaviors that are explicitly or implicitly required (e.g. mentor and support people from different backgrounds, "go along" with others to demonstrate loyalty).

Behavioral expectations are considered to be shared and enduring in nature (Crook \& Szumal, 1993). Such expectations specify the ways members of an organization relate to their work and the ways they relate and interact with one another. Prior research using the 12 OCDI belief sets has consistently demonstrated three sets of clusters constructive, passive-defensive, and aggressive-defensive (Crook \& Lafferty, 1995). Constructive cultures are considered the most productive for diversity (Crook \& Lafferty, 1995). Behaviors associated with defensive cultures are generally considered less productive and less likely to be associated with effective management of diversity (Crook \& Lafferty, 1995). Table 1 identifies the 12 sets of expectations organized by three cluster groups and reports the summary statistics and intercorrelations for the supplier sample. The patterns of correlations within and between the three groups support the three sets of clusters concept. The reliability coefficients for the suppliers were $\mathrm{r}=.82, .72, .59$ and for the buyers $\mathrm{r}=.92, .87, .86$.

\section{FINDINGS}

\section{Tests of Hypotheses}

The literature review supported three demographic factors - ethnicity, gender, and age as potential sources of differences in the perceptions of organizational culture. Table 2 uses ANOVA to provide the tests of hypotheses 
for ethnic minorities $\left(\mathrm{H}_{1}\right)$, gender $\left(\mathrm{H}_{2}\right)$, and age $\left(\mathrm{H}_{3}\right)$. These tests for significant differences in means demonstrate a clear pattern. There are significant differences in means between Caucasian and minority suppliers for seven of the twelve measures of diversity culture. Members of ethnic minorities vs. non-minority buyers are significantly less likely to view the focal organization's culture as humanistic (Mean=23.14 vs. 32.75) and achievement oriented (Mean=27.74 vs. 37.71) - two of four positive characteristics. Further, the minority suppliers are more likely to see the focal organization as passively defensive in terms of being conventional (Mean=27.14 vs. 22.24), being dependent (Mean=23.71 vs. 20.83), and eliciting avoidance behaviors (Mean=21.00 vs. 18.75). Minorities were also likely to view the focal organizational culture as having oppositional aggressive-defensive behaviors (Mean=19.57 vs. 14.65). On six of twelve individual measures of perception of diversity culture $\mathrm{H}_{1}$ is supported. Ethnic minority supplier's perceptions are different and less likely to view the organization as supporting diversity. Contrary to prediction, minority suppliers are less likely to perceive an approval than non-minority suppliers (Mean 20.14 vs. 21.32).

Table 2 also demonstrated that other demographic groups associated with diversity in supply chains do not have significantly different perceptions of the focal organization culture. There are no significant mean differences for males vs. females or for age differences. It follows, therefore, those hypotheses $\mathrm{H}_{2}$ and $\mathrm{H}_{3}$ are not supported. There are no significant differences in the perceptions of culture of diversity associated with these two demographic groupings within the supplier sample.

\section{Exploratory Analysis}

The number and size of the differences of the mean perceptions of cultural differences suggest that additional analysis of minority groups may provide additional insights. Table 3 seeks to subdivide the ethnic minority category into additional subgroups and to compare them for differences with their direct counterparts buyers of the focal organization. In the supplier example, chief executive officers of supplier companies, there are three African-American, two Hispanic, one Native American, and one Asian respondents. The total number of nonminority buyers in the buyer sample is 67.

Minority chief executives officers are, by definition, a low frequency phenomena. Valid testing for differences in small samples can be accomplished, however, using non-parametric tests of significance for differences in means. The permutation Wilcox Method (Weerahandi, 1995) maximizes the available data by looking at all of the possible comparisons (e.g. 67 by 4), looking at the expected number of positive differences $\left(\mathrm{T}_{0}\right.$ ), and comparing the observed positive differences ( $T$ ) to these expectations. The obtained $\mathrm{p}$ values indicated the probability of obtaining observed variations from the expectations.

Significant effects (Table 3) are found for five of twelve culture dimensions for African-Americanshumanistic $(\mathrm{p}<.005)$, achievement $(\mathrm{p}<.029)$, dependence $(\mathrm{p}<.04)$, power $(\mathrm{p}<.035)$, and dependent avoidance $(\mathrm{p}<.02)$. Two of these differences, humanistic and achievement, describe the constructive cultural subset — the subset most associated with building a diverse supply chain. Simply stated, these findings indicate African-American supplier executives are less likely to perceive the buying organization's positive cultural elements than their buyer counterparts. Interestingly, while not perceiving the positive cultural attribute, the Caucasian buyers perceive African-American supplier CEO's, perceive significantly less defensive dimensions.

Significant effects are also noted for Hispanics. They differ from the Caucasian buyers in the perceptions of the focal organizational culture in four cultural dimensions - approval $(\mathrm{p}<.032)$, conventional $(\mathrm{p}<.003)$, avoidance ( $\mathrm{p}<.023$ ), and oppositional (p.009) behavioral expectations. Hispanic supplier executives have a yet different perspective of buyer organization cultures. Hispanics see the focal organization as substantially more defensive. Two other minority categories, Native American and Asian do not demonstrate significant differences from the Caucasian buyers in their perceptions of cultures for diversity. 
Table 1

\begin{tabular}{|c|c|c|c|c|c|c|c|c|c|c|c|c|c|c|c|}
\hline \multicolumn{16}{|c|}{ OCDI Descriptive Statistics and Correlations for Suppliers ${ }^{\mathrm{a}}$} \\
\hline & Culture Style & Mean & SD & 1 & 2 & 3 & 4 & 5 & 6 & 7 & 8 & 9 & 10 & 11 & 12 \\
\hline \multicolumn{16}{|c|}{ Constructive } \\
\hline 1 & Humanistic & 31.73 & 9.638 & --- & & & & & & & & & & & \\
\hline 2 & Affiliative & 37.96 & 8.617 & .764 & --- & & & & & & & & & & \\
\hline 3 & Achievement & 36.43 & 8.387 & .791 & .865 & --- & & & & & & & & & \\
\hline 4 & Self-Actualizing & 32.84 & 9.216 & .784 & .833 & .870 & --- & & & & & & & & \\
\hline \multicolumn{16}{|c|}{ Passive - Defensive } \\
\hline 5 & Approval & 20.73 & 7.100 & .243 & .051 & 0.25 & .027 & --- & & & & & & & \\
\hline 6 & Conventional & 22.86 & 7.583 & -.033 & -.094 & -.171 & -.178 & .729 & --- & & & & & & \\
\hline 7 & Dependent & 21.05 & 7.903 & .011 & -.211 & -.170 & -.184 & 689 & .819 & --- & & & & & \\
\hline 8 & Avoidance & 19.01 & 6.351 & .011 & -.024 & -.058 & -.030 & 636 & .735 & 698 & --- & & & & \\
\hline \multicolumn{16}{|c|}{ Aggressive - Defensive } \\
\hline $9^{\circ}$ & Oppositional & 14.93 & 4.977 & 4.977 & -.128 & -.070 & -.007 & .490 & .614 & .603 & .478 & --- & & & \\
\hline 10 & Power & 20.13 & 7.278 & 7.278 & .002 & .068 & .179 & .632 & .570 & .606 & .550 & .630 & --- & & \\
\hline 11 & Competitive & 18.24 & 6.896 & 6.896 & -.175 & -.075 & -.051 & .624 & .585 & .664 & .552 & .603 & .743 & --- & \\
\hline 12 & Perfectionistic & 27.93 & 7.486 & 7.486 & .139 & .194 & .193 & .622 & .563 & .620 & .639 & .304 & .602 & .674 & --- \\
\hline
\end{tabular}

${ }^{\mathrm{a}} \mathrm{N}=67$, all correlations greater than or equal to .243 are significant at .05 , all correlations greater than or equal to .478 are significant at .01 . 
Table 2

Differences in Supplier Perceptions of Buying Organization Culture by Demographic Differences

\begin{tabular}{|c|c|c|c|c|c|c|c|}
\hline \multirow{2}{*}{\multicolumn{2}{|c|}{ Culture Style }} & \multicolumn{2}{|c|}{ Caucasian vs. Minority } & \multicolumn{2}{|c|}{ Males vs. Females } & \multicolumn{2}{|c|}{ Age } \\
\hline & & $\mathbf{F}^{\mathbf{a}}$ & Sign & $\mathbf{F}^{\mathbf{b}}$ & Sign & $\mathbf{F}^{\mathbf{c}}$ & Sign \\
\hline \multicolumn{8}{|c|}{ Constructive } \\
\hline 1 & Humanistic & 2.975 & $.027 *$ & .000 & .985 & .898 & .448 \\
\hline 2 & Affiliative & 1.789 & .145 & 1.787 & .186 & .823 & .486 \\
\hline 3 & Achievement & 3.448 & $.014 *$ & .030 & .862 & .514 & .674 \\
\hline 4 & Self-Actualizing & 2.171 & .085 & .395 & .532 & 2.053 & .116 \\
\hline \multicolumn{8}{|c|}{ Passive - Defensive } \\
\hline 5 & Approval & 2.789 & $.035 *$ & .565 & .455 & .340 & .796 \\
\hline 6 & Conventional & 9.042 & $.000 * *$ & .476 & .493 & .935 & .430 \\
\hline 7 & Dependent & 5.900 & $.001 * *$ & .996 & .322 & .552 & .649 \\
\hline 8 & Avoidance & 7.079 & $.000 * *$ & 2.334 & .132 & .064 & .979 \\
\hline \multicolumn{8}{|c|}{ Aggressive - Defensive } \\
\hline 9 & Oppositional & 12.830 & $.000 * *$ & .501 & .482 & .459 & .712 \\
\hline 10 & Power & 1.856 & .132 & 1.325 & .254 & 1.316 & .278 \\
\hline 11 & Competitive & 2.262 & .074 & 1.643 & .205 & 1.271 & .293 \\
\hline 12 & Perfectionistic & .489 & .744 & 1.789 & .186 & 1.048 & .378 \\
\hline
\end{tabular}

c 3,60

* significant at .05

** significant at .01 
Table 3

Comparing Perceptions of Ethnic Top Executives of Suppliers With Perception of Caucasian Buyers ${ }^{1}$

\begin{tabular}{|c|c|c|c|c|c|c|c|c|c|c|c|c|c|c|}
\hline \multicolumn{15}{|c|}{ Comparing Perceptions of Ethnic Top Executives of Suppliers With Perception of Caucasian Buyers } \\
\hline & \multirow{2}{*}{ Culture Style } & \multirow{2}{*}{$\begin{array}{r}\text { Buyers }^{2} \\
\ldots \mathrm{x}\end{array}$} & \multicolumn{3}{|c|}{$\underline{\text { African-Americans }}^{2}$} & \multicolumn{3}{|c|}{$\underline{\text { Hispanics }}$} & \multicolumn{3}{|c|}{$\underline{\text { Native Americans }^{2}}$} & \multicolumn{3}{|c|}{$\underline{A s i a n s}^{2}$} \\
\hline & & & $=\mathbf{x}$ & $\mathbf{T} / \mathbf{T}_{\mathbf{0}}$ & $\mathbf{p}$ & $=\mathbf{x}$ & $\mathbf{T} / \mathbf{T}_{\mathbf{0}}$ & $\mathbf{P}$ & $\mathbf{x}$ & $\mathbf{T} / \mathbf{T}_{\mathbf{0}}$ & $\mathbf{p}$ & $\mathbf{x}$ & $\mathbf{T} / \mathbf{T}_{\mathbf{0}}$ & $\mathbf{P}$ \\
\hline \multicolumn{15}{|c|}{ Constructive } \\
\hline 1 & Humanistic & 31.91 & 18.33 & $13.5 / 100.5$ & $.005^{* *}$ & 23.50 & $33.5 / 67.0$ & .267 & 18.00 & $3.5 / 33.5$ & .176 & 42.00 & $62.0 / 33.5$ & .235 \\
\hline 2 & Affiliative & 35.77 & 30.33 & $61.0 / 100.5$ & .267 & 28.50 & $39.5 / 67.0$ & .367 & 26.00 & $10.5 / 33.5$ & .382 & 39.00 & $43.0 / 33.5$ & .794 \\
\hline 3 & Achievement & 34.78 & 25.73 & $27.5 / 100.5$ & $.029^{*}$ & 25.50 & $34.5 / 67.0$ & .280 & 23.00 & $5.5 / 33.5$ & .206 & 43.00 & $61.0 / 33.5$ & .235 \\
\hline 4 & Self-Actualizing & 29.31 & 22.67 & $54.5 / 100.5$ & .195 & 23.00 & $37.5 / 67.0$ & .332 & 22.00 & $13.0 / 33.5$ & .412 & 40.00 & $63.0 / 33.5$ & .176 \\
\hline \multicolumn{15}{|c|}{ Passive/Defensive } \\
\hline 5 & Approval & 23.70 & 13.00 & $10.0 / 100.5$ & .002 & 33.00 & $123.5 / 67.0$ & $.032^{*}$ & 18.00 & $13.5 / 33.5$ & .441 & 18.00 & $13.5 / 33.5$ & .441 \\
\hline 6 & Conventional & 28.56 & 20.33 & $46.0 / 100.5$ & .119 & 47.00 & $130.0 / 67.0$ & $.009^{* * *}$ & 15.00 & $2.5 / 33.5$ & .147 & 20.00 & $9.0 / 33.5$ & .294 \\
\hline 7 & Dependent & 28.40 & 15.67 & $31.0 / 100.5$ & $.040^{*}$ & 42.50 & $118.0 / 67.0$ & .069 & 20.00 & $11.0 / 33.5$ & .382 & 14.00 & $1.5 / 33.5$ & .088 \\
\hline 8 & Avoidance & 24.28 & 14.33 & $25.0 / 100.5$ & $.023^{*}$ & 38.00 & $132.5 / 67.0$ & $.003^{* *}$ & 14.00 & $7.5 / 33.5$ & .294 & 14.00 & $7.5 / 33.5$ & .294 \\
\hline \multicolumn{15}{|c|}{ Aggressive/Defensive } \\
\hline $9^{\circ}$ & Oppositional & 17.26 & 13.00 & 48.0/99.0 & .143 & 34.00 & $127.5 / 66.0$ & $.009^{* * *}$ & 13.00 & $15.5 / 33.0$ & .597 & 17.00 & $36.5 / 33.0$ & .985 \\
\hline 10 & Power & 24.01 & 15.00 & $29.0 / 100.5$ & $.035^{*}$ & 32.00 & $108.5 / 67.0$ & .159 & 19.00 & $18.0 / 33.5$ & .588 & 22.00 & $27.0 / 33.5$ & .853 \\
\hline 11 & Competitive & 23.33 & 20.67 & $83.5 / 100.5$ & .652 & 31.50 & $110.5 / 67.0$ & .138 & 13.00 & $4.5 / 33.5$ & .206 & 19.00 & $23.5 / 33.5$ & .765 \\
\hline 12 & Perfectionistic & 32.42 & 26.11 & $53.0 / 100.5$ & .180 & 31.50 & $53.0 / 67.0$ & .663 & 25.00 & $8.5 / 33.5$ & .324 & 20.00 & $4.0 / 33.5$ & .147 \\
\hline
\end{tabular}

${ }^{1}$ Using Permutation Wilcoxon Method, ${ }^{*}$ significant at $.05,{ }^{* * *}$ significant at $.01, \mathrm{~T}=$ Number of positive differences, $\mathrm{T}_{0}=$ Expected by chance

${ }^{2}$ Buyers $n=67$, African-American $n=3$, Hispanics n=2, Native Americans $n=1$, Asians $n=1$. 


\section{CONCLUSION}

The predicted impact of ethnic minority status on perceptions of cultures of diversity is supported in this test - minority supplier CEOs see the purchasing organization culture different than Caucasian supplier CEOs. Further, these minority CEOs see the focal organization differently than the buyers within the purchasing organization. Previous research even suggested that it would be the two largest ethnic groups - African-American and Hispanic - that would be most likely to perceive organizational cultures differently. Distinctive communication patterns, differences in processing information and different perceptions regarding marketing strategies are given as explanatory concepts behind these perceptual differences (Eroglu, et al.; Helms \& Stern, 2001).

The failure to find significant perceptual differences for gender and age are interesting. The supplier group includes 13 female CEOs. The lack of significant differences between males and females supports one study (Pullins, Reid, \& Plank, 2004, p.40) where differences among buyer/seller business attitudes were "not managerially significantly" for gender. In this case, perhaps women rising to the level of CEO have broadly developed assessments that are more role related than gender related. Failure to find age related differences in this diverse CEO sample (e.g. 19 under the age of 40, 24 ages 40-49, and 21 over age 50), may rest with a more complex understanding of organizational perceptions. Generational perceptions and beliefs may not be simply an age linear phenomena. For example, oldest and youngest voters (e.g. Generation X and the Greatest Generation) share high levels of confidence in financial and scientific institutions not shared by the in between generation. Temporally adjacent generations, Generation X and Baby Boomers, share liberal social attitudes (Farrell and Farrell, 2009). Both the gender and age demographic relationships warrant further study to fully understand cultures of diversity.

There is some cause for optimism among these findings of perceptual differences. Between the nonminority buyers and the African-American supplier CEOs the significant difference is that these suppliers see the buyer culture as less constructive. The African-American CEOs see less passive defensiveness and less aggressive defensiveness than the buyers. For the African-American, the views are different from Caucasians but not extreme or polar opposite. The Hispanic minority CEOs perceptions are more divergent from the perceptions of Caucasian buyers. For the Hispanic supplier CEOs, the buying organization culture appears defensive to cultural diversity. In nine of ten measures of cultural defensiveness, Hispanic suppliers find more defensiveness than buyers, three of passive-defensive dimensions being statistically significant, two at $\mathrm{p}<.01$. Aggressive-defensive dimensions are statistically significant; only once each for African-American and Hispanic supplier CEOs. Stretching the interpretation of the ethnic group findings allows comparison success in other important organizational cultures. A recent study of the future of graduate education (Commission on the Future of Graduate Education, 2010) demonstrates that Asians attain the greatest ethnic within group percentage college enrollment followed by, in order, Caucasians, African-American and Hispanics.

Future research may build on these findings. While there are statistically significant findings based on statistical tests appropriate for the challenges of testing where sample groups will always be small, future research is needed to replicate these findings. The power of these tests remains in question because the size of the population of minority CEOs is not known. Future research might also address methods for reducing perceptional differences in organizational cultures. The buyer-seller relationship includes substantial performance feedback. Feedback is understood as key in developing organizational relationships. Poorly timed or ill-phrased communication has been linked with perceptions of defensive cultures. When defenses are reduced, "receivers become better able to concentrate upon the structure, the content, and the cognitive meanings of the message" (Smith, 2008, p. 9). Regular surveys regarding organization climate or culture, seminars and workshops, special institutes, and a strong corporate philosophy of valuing dissimilarity have also been linked to improved cultures of diversity.

Having a strong supportive culture of diversity, as these findings have shown, is not sufficient to build a strong, diverse, functioning supply chain. Successful firms must move beyond just building a positive culture and also work to share and clarify their culture fully and accurately to minority suppliers. The best cultures of diversity adopt programs of acculturation that reach out, accept, communicate, align, and support ethnic minority businesses. 


\section{ACKNOWLEDGEMENTS}

The authors thank Drs. Magdalena Niewladomska-Bugaj and Rajib Paul for their assistance with the statistical analysis.

\section{AUTHOR INFORMATION}

Gwendolyn Whitfield is currently Vice-President of Organizational Development for Ingram Micro, a New York Stock Exchange Fortune 100 company and leading distributor in the information technology industry. Gwen oversees leadership development, talent management, executive assessment, succession planning and learning development. She is currently a supporting faculty member at the Graziadio School of Business and Management, Pepperdine University.

Dan Farrell is a Professor of Management and Coordinator of the Human Resource Management Program, Haworth College of Business, Western Michigan University. Dan's most recent research concerns the validity of internet surveys and the demise of telephone polling. His other research has centered on the effects of organizational commitment including organizational politics, employee turnover, and absenteeism.

\section{REFERENCES}

1. Ambrose, E., Marshall, D., Fynes, B., \& Lynch, D. (2008). Communications media selection in buyersupplier relationships. International Journal of Operations \& Production Management, 28, 4, 360-379.

2. Barinaga, E. (2007). Cultural diversity at work: 'National Culture' as a discourse organizing an international project group. Human Relations, 60, 315-340.

3. Bowersox, D., Closs D., \& Stank T. (2003). Understanding and mastering...enterprise... on active supply chain management. Supply Chain Management Review, 7, 4, 18-29.

4. Bryant, S.E. \& Terborg, J.R. (2008). Impact of peer mentor training on creating and sharing organizational knowledge. Journal of Managerial Issues, 20, 1, 11-29.

5. Burgess, K., Singh, P.J., \& Koroglu, R. (2006). Supply chain management: a structured literature review and implications for future research. International Journal of Operations \& Production Management, 26, 7, 703-729.

6. Buttner, E.H., Lowe, K.B. \& Billings-Harris, L. (2006). The influence of organizational diversity orientation and leader attitude on diversity activities. Journal of Managerial Issues, 18, 3, 356-371.

7. Chatman, J.A., Polzer, J.T., Barsade, S.G., \& Neale, M.A. (1998). Being different yet feeling similar: The influence of demographic composition and organizational culture on work processes and outcomes. Administrative Science Quarterly, 43, 4, 749-780.

8. Comer, L.B. \& Jolson, M.A. (1991). Perceptions of gender stereotypic behavior: An exploratory study of women in selling. The Journal of Personal Selling and Sales Management, 11, 1, 43-59.

9. Commission on Future Graduate Education in the United States. (2010). The Path Forward: The future of graduate education in the United States. April.

10. Crook, R.A., Giunipero, L., Reus, T., Handfield, R., \& Williams, S. (2008). Antecedents and outcomes of supply chain effectiveness: an exploratory investigation. Journal of Managerial Issues, 20, 2, 161-177.

11. Crook, R.A. \& Lafferty, J.C. (1995). Level One: Lifestyles Inventory - An instrument for assessing and changing the self-concept or organizational members. Lifestyles Inventory Leaders Guide. Human Synergistics, Plymouth, MI.

12. Crook, R.A. \& Szumal, J.L. (1998). Measuring normative beliefs and shared behavioral expectations: A quantitative approach to the assessment of organizational culture. Group and Organizational Studies, 13, 245-273.

13. Dozbaba, S.M. (2000). Successful minority supplier programs. Purchasing Today, September, 52.

14. Dwyer, S., Orlando, R., \& Shepherd, C.D. (1998). An exploratory study of gender and age matching in the salesperson - prospective customer dyad: Testing similarity - performance predictions. The Journal of Personal Selling \& Sales Management, 18, 4, 55-69.

15. Elkins, T.J., Phillips, J.S., \& Ward, S.G. (2008). Organizational sexual harassment investigations: observers' perceptions of fairness. Journal of Management, 20, 1, 88-109. 
16. Endres, M.L., Chowdhury, S.K., \& Alam, I. (2008). Gender effects on bias in complex financial decisions. Journal of Managerial Issues, 20, 2, 238-254.

17. Enz, C.A., Dollinger, M.J., \& Daily, C.M. (1990). The Value Orientations of Minority and Non-Minority Small Business Owners. Entrepreneurship Theory and Practice, 15, 1, 23-35.

18. Eroglu, S., Green Thornton, C., \& Bellenger, D. (2005). Impact of Ethnicity on Management and Channel Building in Minority Enterprises. Journal of Marketing Channels, 12, 3, 27-52.

19. Farrell, D. \& Farrell, C. (2009). Does age produce wisdom in jurors? Michigan Defense Quarterly, 26, 2, 69.

20. Fiol, C.M. (1991). Managing Culture as a Competitive Resource: An Identity-Based View of Sustainable Competitive Advantage. Journal of Management, 17, 1, 1991-211.

21. Fraser, C. \& Zarkada-Fraser, A. (2003). Investigating the effectiveness of managers through an analysis of stakeholder perceptions. Journal of Management, 22, 9, 762-784.

22. Golicic, S. \& Mentzer, J. (2005). Exploring the Drivers of Interorganizational Relationship Magnitude. Journal of Business Logistics, 26, 2, 47-71.

23. Gomez-Mejia, L. \& Palich, L. (1999). A theory of global strategy and firm efficiencies: Considering the effects of cultural diversity. Journal of Management, 25, 4, 587-606.

24. Hartenian, L.S. \& Gudmundson, D.E. (2000). Cultural diversity in small business: Implications for firm performance. Journal of Developmental Entrepreneurship, 5, 3, 209-219.

25. Helms, M.M. \& Stern, R. (2001). Exploring the factors that influence employees' perceptions of their organization's culture. Journal of Management in Medicine, 15, 6, 415-429.

26. Hollowell, B.J. (2007). Examining the relationships between diversity and firm performance. Journal of Diversity Management, 2, 2, 51-59.

27. Jansen, K.J. \& Kristof-Brown, A. (2006). Toward a multidimensional theory of person-environment fit. Journal of Managerial Issues, 18, 2, 193-213.

28. Kaufman, R. (2001). A triangulation approach to diversity supplier development. Best Practices in Publishing and Supply Chain Management, 12, 13-16.

29. Koulikoff-Souviron, M., \& Harrison, A. (2007). The pervasive human resource picture in interdependent supply relationships. International Journal of Operations \& Production Management, 27, 1, 8-27.

30. Lankau, M.J., Ward, A., Amason, A., Ng, T., Sonnefeld, J.A., \& Agle, B.R. (2007). Examining the impact of organizational value dissimilarity in top management teams. Journal of Managerial Issues, 19, 1, 11-35.

31. Low, P.K.C. (2004). The value of diversity: the Kazakhstan perspective. Journal of Management Development, 26, 7, 683-699.

32. Marlin, D., Lamont, B.T., \& Geiger, S.W. (2004). Diversification strategy and top management team fit. Journal of Managerial Issues, 16, 3, 361-383.

33. Marshall, G.W., Stamps, M.B., \& Moore, J.N. (1998). Preinterview biases: The impact of race, physical attractiveness, and sales job type on preinterview impressions of sales job applicants. The Journal of Personal Selling \& Sales Management, 18, 4, 21-38.

34. Martin, C.A. (2005). Racial diversity in professional selling: an empirical investigation of the differences in the perceptions and performance of African-American and Caucasian salespeople. The Journal of Business \& Industrial Marketing, 20, 6, 285-296.

35. McAfee, R.B., Glassman, M., \& Honeycutt, E.D. (2002). The effects of culture and human resource management policies on supply chain management strategy. Journal of Business Logistics, 23, 1, 1-17.

36. McCarty Kilian, C. \& Hukai, D. (2005). Building diversity in the pipeline to corporate leadership. Journal of Management Development, 24, 2, 155-168.

37. Mello, J.E., \& Stank, T.P. (2005). Linking firm culture and orientation to supply chain success. International Journal of Physical Distribution \& Logistics Management 35(8):542-554.

38. Miller, E. (1998). Strategic culture change: The door to achieving high performance culture and inclusion. Public Personnel Management, 27, 151-160.

39. Morgan, J. (2005). Minority supplier development in action: Problems and solutions in corporate programs. Purchasing, August, 49.

40. Ofori-Diankwa. J. \& Reddy, S. (2007). Diversity management using dissimilarity paradigm: A case study of a major mid-west food retailer and distribution company. Journal of Diversity Management, 2, 2, 61-66.

41. Pullins, E.B., Reid, D.A., \& Plank, R.E. (2004). Gender issues in buyer-seller relationships: Does gender matter in purchasing? Journal of Supply Chain Management, 40, 3, 40-48. 
42. Sheu, C., Yen, H.R., \& Chae, B. (2006). Determinants of supplier-retailer collaboration: evidence from an international study. International Journal of Operations \& Production Management, 26, 1, 24-49.

43. Smith, D.C. (2008). Teaching managers to relate: Using feedback to bolster commitment and morale. Journal of Diversity Management, 3, 3, 7-12.

44. Stalinski, S. (2004). Leveraging diversity: Moving from compliance to performance. The Journal for Quality and Participation 27, Winter, 14.

45. Stock, G., \& McDermott, C. (2000). Implementing advanced manufacturing technology: The role of organizational culture. Production and Inventory Management Journal, 41, 3, 66-72.

46. U.S. Department of Labor, Women's Bureau. (2004). Government fact sheet. www.dol.gov/wb/factsheets/qf-laborforce-04.htm

47. U.S. Small Business Administration Office of Advocacy. (2001). Minorities in Business. Washington, D.C.

48. Weerahand, S. (1995). Exact Statistical Methods for Data Analysis. Springer, NY.

49. Whitfield, G. \& Landeros, R. (2006). Supplier diversity effectiveness: Does organizational culture really matter? The Journal of Supply Chain Management, Fall, 16-28.

50. Yuva, J. (2003) Essential factors to a supplier diversity initiative. Inside Supply Management, 14, 8. 


\section{NOTES}

